\title{
Koefisien Absorbsi Bunyi dan Impedansi Akustik dari Ampas Singkong (Manihot esculenta) dengan Menggunakan Metode Tabung
}

\author{
Yulia Rezita*, Elvaswer, Rahmat Rasyid \\ Laboratorium Fisika Material, Jurusan Fisika, FMIPA, Universitas Andalas \\ Fakultas Matematika dan Ilmu Pengetahuan Alam Universitas Andalas \\ Kampus UNAND Limau Manis, Padang, 25163 \\ *yuliarezita60@gmail.com
}

\begin{abstract}
ABSTRAK
Telah dilakukan penelitian untuk menentukan koefisien absorbsi bunyi dan impedansi akustik dari material ampas singkong dengan matriks lem PVC dengan menggunakan metode tabung. Sampel material akustik yang dibuat dari ampas singkong dengan variasi ketebalan $2 \mathrm{~mm}, 4 \mathrm{~mm}, 6 \mathrm{~mm}, 8 \mathrm{~mm}$ dan $10 \mathrm{~mm}$. Pengukuran koefisien absorbs bunyi pada sampel menggunakan frekuensi $500 \mathrm{~Hz}, 1000 \mathrm{~Hz}, 1500 \mathrm{~Hz}$, $2000 \mathrm{~Hz}$ dan $2500 \mathrm{~Hz}$. Hasil penelitian ini menunjukkan nilai koefisien absorbsi bunyi tertinggi adalah 0,98 pada frekuensi $1500 \mathrm{~Hz}$ dengan ketebalan $10 \mathrm{~mm}$ dan nilai terendah adalah 0,64 pada frekuensi 2500 $\mathrm{Hz}$ dengan ketebalan $2 \mathrm{~mm}$. Nilai impedansi akustik tertinggi adalah 2,78 pada frekuensi $1500 \mathrm{~Hz}$ dengan ketebalan $10 \mathrm{~mm}$ dan nilai terendah adalah 1,20 pada frekuensi $2500 \mathrm{~Hz}$ dengan ketebalan $2 \mathrm{~mm}$. Dengan demikian ampas singkong potensial digunakan sebagai bahan penyerap bunyi berdasarkan ISO 11654 suatu material dapat dijadikan peredam suara jika material tersebut memiliki koefisien absorbsi bunyi minimum 0,15 .
\end{abstract}

Kata kunci: ampas singkong, frekuensi, impedansi akustik, koefisien absorbsi bunyi, metode tabung

\section{ABSTRACT}

Research has been carried out to determine the sound absorption coefficient and acoustic impedance of cassava pulp material with PVC glue matrix using the tube method. Acoustic material samples made from cassava pulp with various thicknesses of $2 \mathrm{~mm}, 4 \mathrm{~mm}, 6 \mathrm{~mm}, 8 \mathrm{~mm}$ and $10 \mathrm{~mm}$. The measurement of sound absorption coefficients in the sample uses a frequency of $500 \mathrm{~Hz}, 1000 \mathrm{~Hz}, 1500 \mathrm{~Hz}, 2000 \mathrm{~Hz}$ and $2500 \mathrm{~Hz}$. The results of this study show the highest sound coefficient of absorbs is 0.98 at a frequency of $1500 \mathrm{~Hz}$ with a thickness of $10 \mathrm{~mm}$ and the lowest value is 0.64 at a frequency of $2500 \mathrm{~Hz}$ with a thickness of $2 \mathrm{~mm}$. The highest acoustic impedance value is 2.78 at a frequency of $1500 \mathrm{~Hz}$ with a thickness of $10 \mathrm{~mm}$ and the lowest value is 1.20 at a frequency of $2500 \mathrm{~Hz}$ with a thickness of $2 \mathrm{~mm}$. Thus potential cassava pulp is used as a sound absorber based on ISO 11654, a material can be used as a silencer if the material has a minimum sound absorption coefficient of 0.15 .

Keywords:cassava pulp, frequency, acoustic impedance, sound absorption coefficient, tube method

\section{PENDAHULUAN}

Kebisingan merupakan sumber-sumber suara yang tidak diinginkan dan salah satu masalah lingkungan yang harus diperhatikan. Hal ini dapat dihasilkan oleh alam seperti petir, hujan, hembusan angin dan sebagainya. Kemudian dari peralatan yang ada disekitar kita seperti kendaraan, televisi, mesin pencuci serta alat-alat rumah tangga lainnya dengan frekuensi yang berbeda-beda (Doelle, 1990). Masalah ini dapat dikendalikan dengan menyerap kebisingan tersebut menggunakan berbagai material yang dirancang khusus untuk akustik.

Akustik adalah ilmu yang mempelajari hal-hal yang berkaitan dengan bunyi, berkenaan dengan indra pendengaran serta keadaan ruangan yang mempengaruhi bunyi (Sistiani, 2011). Efisiensi penyerapan bunyi suatu bahan pada frekuensi tertentu dinyatakan oleh koefisien absorbsi bunyi.

Standarisasi nilai koefisien absorbsi pada suatu material sangat penting untuk penerapan material akustik. Koefisien absorbsi merupakan efisiensi penyerapan bunyi suatu material pada frekuensi tertentu, dimana nilainya 0 sampai 1 . Nilai koefisien absorbsi 0 menyatakan tidak ada energi bunyi yang diserap dan nilai koefisien absorbsi 1 menyatakan serapan yang sempurna (Sriwigiyatno, 2006).

Komposit merupakan suatu struktur material yang dapat menggunakan serat sebagai material dasarnya. Serat alami yang digunakan adalah sebagai material penguat yang berfungsi untuk menambah kekuatan dan kekakuan dalam menerima beban yang diinginkan. Serat yang terdapat di alam memiliki sifat-sifat yang cocok sebagai material dasar penguat pada komposit. 
Serat alam memiliki arah-arah serat yang acak dan sulit diatur. Serat alam pada umumnya memiliki kemampuan untuk menyerap bunyi yang cukup baik (Wirajaya, 2007).

(Sinaga dkk, 2012) melakukan penelitian yang berjudul pengukuran absorbsi bunyi dari limbah batang kelapa sawit. Metode yang digunakan adalah metode tabung yang terbuat dari akrilik. Dari penelitian yang dilakukan didapatkan hasil $\alpha=0,2$ pada ketebalan $3 \mathrm{~mm}, \alpha=0,3$ pada ketebalan $9 \mathrm{~mm}$ dan pada $\alpha=0,4$ pada ketebalan $15 \mathrm{~mm}$ pada frekuensi $500 \mathrm{~Hz}$. hal ini menunjukkan bahwa koefisien absorbsi bunyi dipengaruhi oleh ketebalan sampel.

(Eriningsih dkk, 2014) melakukan penelitian tentang pembuatan dan karakterisasi peredam suara dari bahan serat baku dari alam yaitu serat rami, abaka dan kelapa. Dari penelitian tersebut didapatkan hasil koefisien absorbsi bunyi untuk serat rami yaitu $\alpha=0,25$ pada frekuensi $1000 \mathrm{~Hz}$ dan $\alpha=0,5$ pada frekuensi $2000 \mathrm{~Hz}$ dengan ketebalan 13,5 mm. Nilai koefisien absorbsi bunyi pada serat abaka $\alpha=0,65$ pada frekuensi $1000 \mathrm{~Hz}$ dan $\alpha=0,54$ pada frekuensi $2000 \mathrm{~Hz}$ dengan ketebalan 21,1 mm. Nilai koefisien absorbsi bunyi pada serat kelapa $\alpha=0.25$ pada frekuensi $1000 \mathrm{~Hz}$ dan $\alpha=0,84$ pada frekuensi $2000 \mathrm{~Hz}$ dengan ketebalan 30,5 $\mathrm{mm}$.

Penelitian ini dilakukan untuk menentukan nilai koefisien absorbsi bunyi dan impedansi akustik dari campuran material ampas singkong dengan matriks lem PVC. Pengujian akustik dapat dibedakan berdasarkan tempat pengujiannya yakni pengujian di dalam tabung dua mikrofon dan pengujian dalam ruang dengung. Pada penelitian penentuan koefisien absorbsi akustik dilakukan dengan menggunakan metode tabung. Metode tabung dipilih karena praktis dan material yang diperlukan relatif sedikit dibandingkan dengan metode ruang dengung dan metode tabung dua mikrofon.

Koefisien absorbs bunyi $(\alpha)$ dapat dihitung dengan menggunakan Persamaan 1 (Russel, 1999).

$\alpha=1-\left[\frac{S W R-1}{S W R+1}\right]^{2}$

Dengan SWR adalah Standing Wave Rasio. SWR merupakan perbandingan amplitudo tekanan maksimum $(\mathrm{A}+\mathrm{B})$ dengan amplitudo tekanan minimum (A-B), dimana secara matematis dapat dinyatakan pada Persamaan 2

$S W R=\frac{A+B}{A-B}$

Impedansi akustik dihitung dengan menggunakan Persamaan 3.

$Z_{s}=\frac{P(x)}{U(x)}$

Dengan $Z s$ adalah impedansi akustik (dyne.s/cm5). Untuk dapat menentukan impedansi akustik terlebih dahulu harus ditentukan nilai $\Psi 1$ dan $\Psi 2$ yang dapat dinyatakan pada Persamaan 4 dan Persamaan 5.

$\varphi_{1}=\operatorname{coth}^{-1}[\log 10-1(S W R / 20)]$

$\varphi_{2}=\left[\frac{1}{2}-\frac{d_{1}}{d_{2}}\right]$

$\Psi_{1}, \Psi_{2}$ adalah bilangan kompleks, $d_{1}$ adalah jarak amplitudo minimum pertama $(\mathrm{cm})$ dan $d_{2}$ adalah jarak amplitudo dari minimum pertama ke minimum kedua $(\mathrm{cm})$.

II. METODE

\subsection{Pembuatan Komposit Serat Ampas Singkong}

Pembuatan sampel dimulai dengan singkong yang diparut lalu diperas 3-4 kali untuk diambil patinya sehingga tersisa ampas singkong. Ampas singkong dijemur selama 4 jam untuk 
mengurangi kandungan airnya dan dikeringkan dalam oven pada suhu $70{ }^{\circ} \mathrm{C}$ agar didapatkan hasil yang benar-benar kering. Kemudian ampas singkong dicampurkan dengan lem PVC ke dalam lumpang dan diaduk sampai merata selama 10 menit. Setelah merata, sampel dimasukkan kedalam cetakan yang telah dilapisi dengan aluminium foil agar sampel mudah dilepaskan dari cetakan. Sampel didiamkan sampai kering yaitu selama 4 hari.

\subsection{Pengujian Menggunakan Tabung Impedansi}

Penelitian ini menggunakan tabung impedansi untuk mengetahui kemampuan material ampas singkong dalam menyerap bunyi. Tabung impedansi digunakan karena pengoperasiannya yang mudah dan juga material yang diuji berukuran kecil sesuai dengan tabung impedansi. Tabung impedansi yang akan digunakan terbuat dari besi yang dirangkai sedemikian rupa. Dalam pegoperasiannya tabung impedansi ini dihubungkan dengan beberapa alat antara lain: amplifier, osiloskop, generator sinyal, catu daya, mikrofon dan loadspeaker seperti terlihat pada Gambar 1.

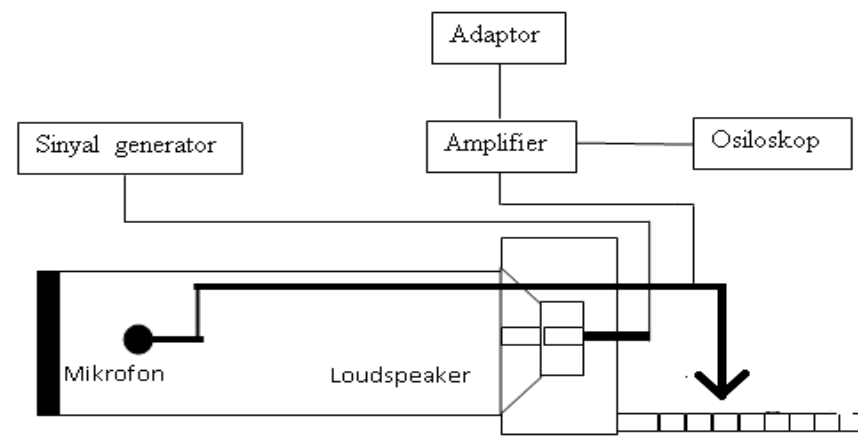

Gambar 1 Skema Rangkaian Tabung Impedansi

Sinyal generator yang dihubungkan dengan louadspeaker menghasilkan output berupa bunyi yang memiliki frekuensi konstan sehingga dapat diatur pada sinyal generator. Mikrofon diperkuat dengan amplifier dan dihubungkan ke osiloskop untuk menampilkan bentuk gelombang yang akan dihitung amplitudo tekanan maksimum $(A+B)$ dan minimumnya (A-B), dan jarak amplitudo minimum pertama $\left(d_{1}\right)$ dan jarak amplitudo minimum kedua. Frekuensi yang digunakan pada penelitian ini adalah $500 \mathrm{~Hz}, 1000 \mathrm{~Hz}, 1500 \mathrm{~Hz}, 2000 \mathrm{~Hz}$ dan $2500 \mathrm{~Hz}$.

\section{HASIL DAN DISKUSI}

\subsection{Hubungan Koefisien Absorbsi Bunyi Terhadap Frekuensi}

Nilai koefisien absorbsi bunyi pada material akustik ampas singkong dapat dilihat pada Tabel 1 dan grafik hubungannya ditampilkan pada Gambar 2.

Tabel 1 Nilai Koefisien absorbsi bunyi material akustik ampas singkong terhadap frekuensi dengan ketebalan yang bervariasi.

\begin{tabular}{|c|c|c|c|c|c|}
\hline \multirow{2}{*}{$\begin{array}{l}\text { Frekuensi } \\
(\text { Hz) }\end{array}$} & \multicolumn{5}{|c|}{ Koefisien Absorbsi Bunyi/Ketebalan } \\
\hline & $2 \mathrm{~mm}$ & $4 \mathrm{~mm}$ & $6 \mathrm{~mm}$ & $8 \mathrm{~mm}$ & $10 \mathrm{~mm}$ \\
\hline 500 & 0,62 & 0,76 & 0,81 & 0.88 & 0,89 \\
\hline 1000 & 0,79 & 0,89 & 0,86 & 0,92 & 0,96 \\
\hline 1500 & 0,87 & 0,93 & 0,92 & 0,95 & 0,98 \\
\hline 2000 & 0,72 & 0,80 & 0,88 & 0,94 & 007 \\
\hline 2500 & 0,64 & 0,70 & 0,79 & 0,86 & 0,90 \\
\hline
\end{tabular}

Material akustik ampas singkong dengan ketebalan yang berbeda memiliki pola penyerapan bunyi yang berbeda pula, dari frekuensi rendah hingga frekuensi tinggi. Koefisien absorbsi bunyi meningkat dengan adanya penambahan ketebalan pada sampel. Nilai koefisien absorbsi paling tinggi didapatkan adalah pada frekuensi $1500 \mathrm{~Hz}$ pada ketebalan $10 \mathrm{~mm}$. 


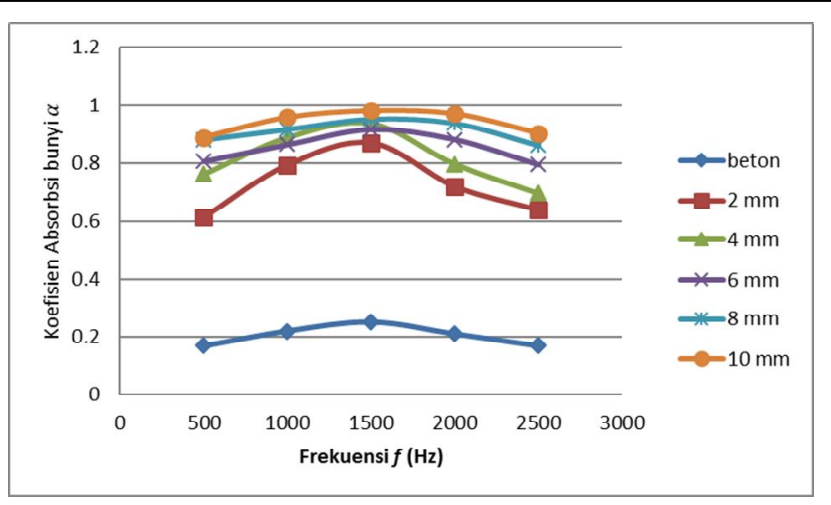

Gambar 2 Hubungan koefisien absorbsi bunyi material akustik ampas singkong terhadap frekuensi $(\mathrm{Hz})$

Nilai koefisien absorbsi pada beton tertinggi adalah 0,25 pada frekuensi $1500 \mathrm{~Hz}$. Pada material akustik ampas singkong tertinggi yaitu 0,98 dengan ketebalan $10 \mathrm{~mm}$ pada frekuensi $1500 \mathrm{~Hz}$. Tingginya nilai koefisien absorbsi dikarenakan pengaruh ketebalan pada sampel. Dengan ketebalan yang lebih besar sehingga sampel juga memiliki pori-pori yang lebih banyak dan volume lebih besar. Gelombang bunyi yang datang masuk ke pori-pori lebih banyak diserap oleh sampel dari pada dipantulkan.

Pada frekuensi $2500 \mathrm{~Hz}$ nilai koefisien absorbsi bunyi yaitu 0,64 pada material akustik ampas singkong dengan ketebalan $2 \mathrm{~mm}$, hal ini disebabkan karena sampel yang sangat tipis dan memiliki pori-pori yang sedikit. Volume pada sampel lebih kecil hingga banyaknya gelombang datang yang dipantulkan. Sehingga rendahnya energi yang diserap dan pendeknya penjalaran gelombang didalam sampel.

Pada frekuensi $500 \mathrm{~Hz}$ hingga $1500 \mathrm{~Hz}$ nilai koefisien absorbsi bunyi meningkat. Hal ini dikarenakan gelombang bunyi masuk kedalam pori maka terjadi pantulan secara acak didalam sampel sehingga amplitudo gelombang pantul melemah. Jika amplitudo tekanan minimumnya meningkat maka bunyi lebih banyak diserap dari pada dipantulkan. Koefisien absorbsi bunyi menurun pada frekuensi $2000 \mathrm{~Hz}$ hingga $2500 \mathrm{~Hz}$. Hal ini dikarenakan pada frekuensi tertentu material akustik cenderung bersifat resesif dimana rendahnya nilai koefisien absorbsi bunyi pada frekuensi tertentu. Amplitudo gelombang pantulnya meningkat, sehingga amplitudo tekanan minimumnya melemah, dan bunyi yang dipantulkan lebih banyak.

\subsection{Hubungan Impedansi Akustik $(Z)$ Terhadap Frekuensi}

Pada frekuensi $500 \mathrm{~Hz}-1500 \mathrm{~Hz}$ nilai impedansi akustik naik dan turun pada frekuensi $2000 \mathrm{~Hz}-2500 \mathrm{~Hz}$. Ini dikarenakan pada frekuensi rendah terjadi penyerapan bunyi yang besar, berbeda dengan frekuensi tinggi gelombang bunyi akan menyebar (dipantulkan dan ditransmisikan) (Lee, 2001). Ketika terjadi penyerapan yang besar, energi bunyi yang dipantulkan lebih sedikit sehingga nilai koefisien absorbsi bunyi tinggi dan nilai impedansi akustik juga tinggi.

Tabel 2 Nilai impedansi akustik $(Z)$ material akustik ampas singkong terhadap frekuensi dengan ketebalan yang bervariasi

\begin{tabular}{cccccc}
\hline \multirow{2}{*}{$\begin{array}{c}\text { Frekuensi } \\
(\mathbf{H z})\end{array}$} & $\mathbf{2} \mathbf{~ \mathbf { m }}$ & $\mathbf{4} \mathbf{~} \mathbf{m m}$ & $\mathbf{6} \mathbf{~ m m}$ & $\mathbf{8} \mathbf{~ m m}$ & $\mathbf{1 0} \mathbf{~ m m}$ \\
\cline { 2 - 6 } Impedansi Akustik/Ketebalan \\
\hline 500 & 1,24 & 1,61 & 1,56 & 1,72 & 2,40 \\
1000 & 1,34 & 1,88 & 1,66 & 2,23 & 2,65 \\
1500 & 1,39 & 2,71 & 2,35 & 2,51 & 2,78 \\
2000 & 1,28 & 1,91 & 1,49 & 2,54 & 2,46 \\
2500 & 1,20 & 1,34 & 1,38 & 2,31 & 2,29 \\
\hline
\end{tabular}




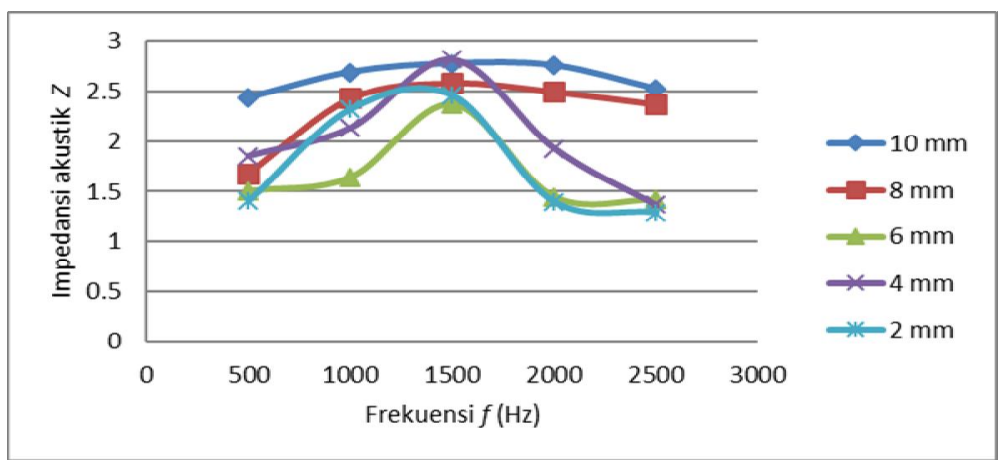

Gambar 3 Hubungan impedansi akustik (Z) terhadap frekuensi ( $f$ )

Gambar 3 menunjukkan nilai impedansi tertinggi yaitu 2,78 pada ukuran sampel $10 \mathrm{~mm}$ pada frekuensi $1500 \mathrm{~Hz}$. Hal ini karena terjadinya penyerapan bunyi yang besar pada sampel yang bervolume lebih besar. Impedansi akustik terendah yaitu 1,20 dengan ketebalan sampel 2 mm pada frekuensi $2500 \mathrm{~Hz}$, karena terjadinya penyerapan bunyi yang kecil pada sampel. Dari data yang diperoleh, dapat diketahui bahwa nilai impedansi akustik sebanding dengan nilai koefisien absorbsi bunyi.

\section{KESIMPULAN}

Berdasarkan penelitian ini dapat disimpulkan bahwa koefisien absorbsi bunyi material akustik ampas singkong tertinggi adalah 0,98 dengan ketebalan $10 \mathrm{~mm}$ dan terendah adalah 0,64 dengan ketebalan $2 \mathrm{~mm}$ pada frekuensi $1500 \mathrm{~Hz}$. Material akustik ampas singkong dapat digunakan sebagai salah satu material pengendali kebisingan, karena berdasarkan ISO 11654 suatu material dapat dijadikan peredam suara jika material tersebut memiliki koefisien absorbsi bunyi minimum 0,15 .

\section{DAFTAR PUSTAKA}

Doelle, E., Akustik Linkungan, (diterjemahkan oleh: Lea Prasetyo), Erlangga, Jakarta, 1990.

Eriningsih, R., Widodo, M. dan Marlina, R., Pembuatan dan Karakterisasi Peredam Suara Dari Bahan Baku Serat Alam, Arena Tekstil, Balai Besar Tekstil, 2014, Hal. 1-8.

Russell, D, A., Absorption Coeffcients and Impedance, Science and Mathematics Department. GMI Engineering and Management Intitute Flint, MI, 48504, 1999.

Sinaga, D., Defriyanto, I., dan Krisman, M., Pengukuran koefisien Absorbsi Bunyi dari Limbah Batang Kelapa Sawit, Jurnal Fisika, UNRI, 2012, hal. 415-423.

Sistiani, D., Pengujian Panel Akustik Komposit Wol Mangium (Acacia Mangium Wild) Berkerapatan Sedang, Skripsi, Institut Pertanian Bogor, Bogor, 2011.

Sriwigiyatno, K., Analisis Pengaruh Kolom Udara terhadap Nilai Koefisien Serapan Bunyi pada Dinding Partisi Menggunakan Metode Tabung Impedansi Dua Mikrofon, Skripsi, UNS, Surakarta, 2006.

Wirajaya, A, Karakteristik Komposit Sandwich Serat Alami Sebagai Absorber Bunyi, Tugas Akhir S1 ITB, Bandung, 2007. 